\title{
Expanded Beds: A Process Solution for Adsorptive Separations in Waste-Water Treatment
}

\author{
Yogeshwar N. Thakare and Arun Kumar Jana
}

\begin{abstract}
Most of the commercial adsorptive separation is carried out in fixed bed mode. A clear and steady feed is required for efficient operation of fixed beds. If the feed carries insoluble matter, it gets trapped in the voids and enhances the pressure drop across the bed. So, a solid-liquid stable fluidized bed termed as expanded bed is getting wide applications in the realm of adsorptive separations. Expanded bed operation is based on controlled stable fluidization, which combines the hydrodynamic properties of fluidized bed along with the plug flow behavior of the packed bed. A comparative performance of packed and expanded beds is studied here for adsorptive separation of copper from waste-water. Impact of operating velocity on column performance is studied in the present work. The results show the proper choice of adsorbent and operating conditions can allow for carrying out adsorptive separations in the expanded bed mode for wastewater treatment with minimum impact on bed efficiency.
\end{abstract}

Index Terms-Expanded bed, fluidization, terminal settling velocity, sedimented bed, copper, waste water.

\section{INTRODUCTION}

Copper is one of the major highly toxic pollutants commonly found in many wastewater sources such as electroplating, printed circuit board manufacturing, wire drawing, copper polishing, paint manufacturing, wood preservatives and printing operations [1]. Its concentrations may vary from ppm level in copper cleaning operations to gram level in waste-water from plating bath. Water pollution is a threat to the living being as many pollutants enter into the ecosystem. The issue of pollutant free water and waste-water is always important, as it has a direct impact on the society. The need to more efficient process for wastewater treatment arises with an increase in industrial activities.

The World Health Organization (WHO) has put stringent norms for copper in potable water, which is below $1.5 \mathrm{mg} / \mathrm{L}$ [2]. As it enters the human body, damages the protein, lipids and DNA by generating reactive free oxygen species [1]. The excessive intake of copper may also result in schizophrenia and the Alzheimer kind of diseases [3]-[5]. Copper has a similar adverse effect on marine ecosystem, damaging aquatic life [6]-[8].

There are various methods for separation of copper from water and wastewater. These are broadly categorized as precipitation, electrochemical techniques and adsorptive

Manscript received July 16, 2013; revised September 11, 2013.

Yogeshwar N. Thakare is with the Reliance Industries Ltd, Hazira and a part time research scholar in the Department of Chemical Engineering, Sardar Vallabhbhai National Institute of Technology, Surat, Gujarat, 395007 India (e-mail: tyogeshwar@gmail.com).

Arun Kumar Jana is with the Department of Chemical Engineering, Sardar Vallabhbhai National Institute of Technology, Surat, Gujarat, 395007 India (e-mail: akj@ched.svnit.ac.in). separations. The selection of the separation process is done based on the concentration of the metal in the waste-water and process economics. Adsorption is preferred method, and mostly bioadsorbents and ion exchange resins are reported as adsorbents. Although, various bioadsorbents are explored as economical option, but still ion exchange resins are preferred choice for the removal of heavy metals from water and wastewater because of high efficiency [9], [10].

Industrially, the adsorptive separations using ion exchange resins are carried out in fixed bed mode. A clear and steady feed is required for efficient operation of fixed beds. If the feed carries insoluble matter, it gets trapped in the voids of the bed and enhances the pressure drop across the bed. Also, trapped impurities can act as a catalyst for growth of biological matter, e.g., accumulation of activated carbon catalyzes algal growth in mixed bed cation exchange of water demineralization unit, adding pressure drop across the bed. Solid-liquid stable fluidized bed termed as expanded bed offers the advantage of higher voidage, which allows particulate matter to pass through it unhindered. As expanded bed adsorption is being successfully used for separating biomolecules from unclarified feedstock [11]-[13]; its applications can be extended for removing trace impurities from waste-water also.

Fluidized beds are unstable, which gives rise to increased axial mixing in liquid phase and lowers the bed efficiency [14]. Expanded beds are stable having minimum axial mixing. The mixing in the bed is imparted by the fluidizing media as well as column design. Solid and liquid phase properties (e.g., particle size, liquid viscosity) along with operating conditions (e.g., liquid velocity) decide the importance of external or internal mass transfer in the column. Smaller particles have a small diffusion path, so lesser is the resistances for mass transfer, on the other hand, large particles have long diffusion paths, so enhanced resistances for internal mass transfer [15]. Higher operating velocity reduces the film resistances but increases bed turbulence. So adsorbent with higher density are preferred for expanded beds. High density matrix remains stable at relatively high velocity.

In the present work adsorptive separation of copper has been studied in packed and expanded bed mode. Batch equilibrium adsorption and expanded bed hydrodynamics are also studied for fixing experimental operating windows.

\section{EXPERIMENTAL}

\section{A. Materials}

Commercial grade copper sulphate $\left(\mathrm{CuSO}_{4} .5 \mathrm{H}_{2} \mathrm{O}\right)$ was procured from Sisco Research Laboratory, Mumbai and used for the adsorption studies. All the other chemicals were 
analytical grade and procured from local vendors. The stock solution of copper was prepared by dissolving copper sulphate in de-mineralized water and used for all experiments with required dilution. The cation exchange matrix INDION225H used in this study is procured from Ion Exchange, Mumbai.

For the studies of adsorption in packed and expanded bed adsorption a glass column of $2.5 \mathrm{~cm}$ diameter and length of $50 \mathrm{~cm}$ is fabricated. Two specially designed stainless steel adaptors with mesh with a size of $100 \mu \mathrm{m}$ are used as a liquid distributor, which can be fixed at desired length in the glass column. A peristaltic pump along with pulsation dampener is used to feed the liquid to the column. Bed expansion studies are carried out for INDION225H resin by using water as the fluidizing medium and for adsorption studies $1 \%$ copper sulphate solution is fed to the column.

\section{B. Methods}

\section{1) Equilibrium adsorption studies}

Equilibrium adsorption studies are carried out to determine the capacity of adsorption on ion exchange resins. For equilibrium studies, the stock solution of copper sulphate was diluted to different concentrations. Adsorption isotherm studies were carried out in a series of $100 \mathrm{~mL}$ reaction bottles. Each reaction bottles was filled with $50 \mathrm{~mL}$ of solution with different initial concentrations and the constant resin dosage of $5 \mathrm{~mL}$ was maintained. The mixture was stirred at $200 \mathrm{RPM}$ for a predetermined time in the shaking incubator. The incubator was maintained at a fixed temperature of $30^{\circ} \mathrm{C}$. After the equilibrium, the resins were filtered off and the filtrate was analyzed using spectrophotometer at $600 \mathrm{~nm}$.

Solution temperature and concentration of solute are the two major process parameters, deciding the extent of adsorption. The phenomenon of solute adsorption from solution of constant concentration and function of temperature could be explained by adsorption thermodynamics. The adsorption of solute studied at a constant temperature as a function of concentration of the feed could be explained by adsorption isotherms. There are various isotherms [16] like Freundlich, Langmuir, Redlich-Peterson, Temkin and Dubinin-Redushkevich isotherms proposed to explain this phenomenon.

\section{2) Bed expansion studies}

To study the bed expansion a fixed amount of adsorbent (INDION225H) is used for expansion as well as adsorption studies. Demineralized water is used as a fluidizing medium and fed to the column by using a peristaltic pump.

Bed expansion $(E)$ is expressed as the ratio of the expanded bed height $(H)$ to the settled or sedimented bed height $\left(H_{0}\right)$ i.e., and it is plotted against the superficial velocity of the liquid.

$$
E=\frac{H}{H_{0}}
$$

Bed voidage as a function of superficial velocity is obtained by,

$$
E=\frac{(1-\varepsilon)}{\left(1-\varepsilon_{0}\right)}
$$

where, $\varepsilon_{0}$ is sedimented bed voidage and $\varepsilon$ is expanded bed voidage.

Bed expansion characteristics such as terminal settling velocity and Richardson-Zaki index is obtained from Richardson-Zaki equation [17] as,

$$
U=U_{t}(\varepsilon)^{n}
$$

where, $U(\mathrm{~cm} / \mathrm{s})$ is liquid superficial velocity and $U_{t}(\mathrm{~cm} / \mathrm{s})$ is terminal settling velocity of the particles.

\section{3) Dynamic copper adsorption in packed and expanded beds}

Breakthrough studies for copper adsorption from copper sulphate solution are carried out in packed and expanded bed mode. For operation in a packed bed mode, both adaptors are fixed close to the resin when there is no liquid in the bed. Breakthrough studies are carried out by passing a solution in the upward direction through the column. Experimental setup is as shown in Fig. 1.

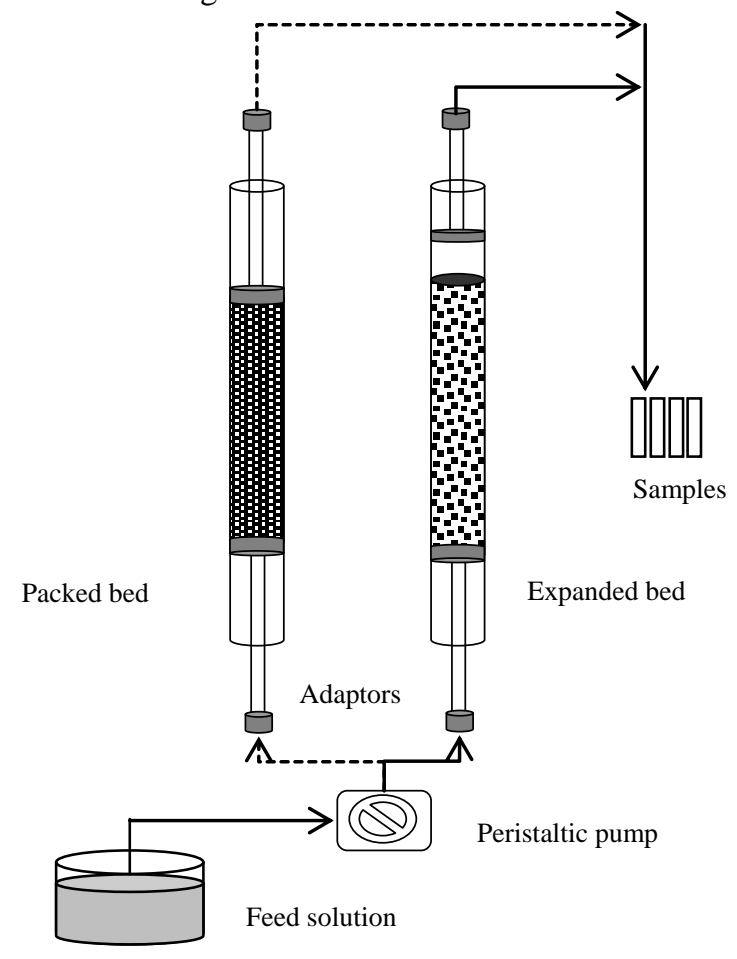

Fig. 1. Experimental setup for packed and expanded bed studies

Bed with fixed resin loading $\left(H_{0}=23 \mathrm{~cm}\right)$ is operated at different feed velocity (feed flow rate of 10, 30, 50, 70 and 90 $\mathrm{mL} / \mathrm{min}$ ) and constant solute loading of $1 \%$ to study its impact on adsorption and column efficiency. Fractions are collected till constant residual concentration of copper is in the raffinate. Expanded bed mode adsorption studies are carried out in the similar conditions, but top adaptor in the column is fixed at $12 \mathrm{~cm}$ higher than the resin bed at a stationary condition. It allows expansion of the bed with varying liquid velocity. Fractions are analyzed for absorbance at $600 \mathrm{~nm}$ wavelength by spectrophotometer.

The efficiency of an adsorbent bed is measured in terms of broadening of a finite solute band as it travels through the length of the column. Lesser the band broadening higher is the column efficiency. The HETP (Height Equivalent to Theoretical Plate), the number of theoretical plates and overall rate of mass transfer from the mobile phase to adsorbent phase under operating conditions reflects the efficiency of a bed in static fixed or expanded state. HETP can be estimated from frontal adsorption experiments, which gives the solute breakthrough profile as shown in Fig. 2. 
The number of theoretical plates can be calculated as [18],

$$
N=16\left[\frac{V_{R}}{V_{R}-V_{R}}\right]^{2}
$$

where, $V_{R}$ is the retention volume read as the volume of effluent at the inflection point on the breakthrough curve of concentration against eluted volume. $V_{E}$ and $V_{B}$ are the eluent volumes at breakthrough and exhaustion points on the curve (also shown in the Fig. 2).

In frontal adsorption all of the column length $L$ is not adsorbing the solute at any given time. Height of the active adsorption zone $L_{a}$ in the column is given as [18],

$$
L_{a}=L\left[\frac{\left(V_{E}-V_{B}\right)}{\left(V_{E}-(1-f)\left(V_{E}-V_{B}\right)\right)}\right]
$$

where $f$ is the fractional ability of the adsorbent to adsorb the solute and given as [18],

$$
f=\frac{W_{a}}{w}
$$

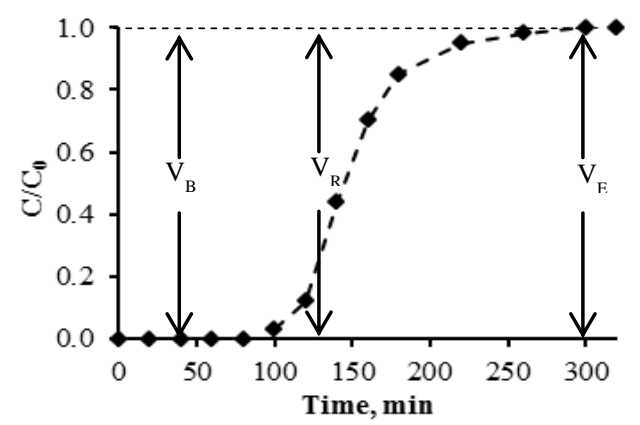

Fig. 2. Breakthrough curve profile showing volume at a breakthrough point $\left(V_{B}\right)$, volume at the exhaust point $\left(V_{E}\right)$ and retention volume $\left(V_{R}\right)$

where $W_{a}$ and $W$ are the amount of solute adsorbed and total solute loaded during the breakthrough period respectively. These quantities may also be estimated as below [18].

$$
\begin{aligned}
& W=C_{i}\left(V_{E}-V_{B}\right) \\
& W_{a}=W-\alpha
\end{aligned}
$$

$C_{i}$ is the concentration of the solute in the feed and $\alpha$ is the area under breakthrough curve in the period from breakthrough to exhaustion. $W_{a}$ is the amount of solute that comes through un-adsorbed during the breakthrough period and can be estimated from the eluent fractions pooled during breakthrough.

HETP is calculated by using the following equation according to [17].

$$
\text { HETP }=\frac{L_{a}}{N}
$$

As HETP is an indicator of column performance, lower the value better is the bed efficiency.

\section{RESULTS AND DISCUSSIONS}

\section{A. Batch Adsorption Studies}

Equilibrium plot for adsorption of copper on the INDION225H ion exchange resin is shown in Fig. 3. The experimental data is analyzed using Redlich-Peterson isotherm [16] as it gives the best fit amongst all the adsorption isotherms. It is a three parameter hybrid model for adsorption by combining the parameters of Langmuir and Freundlich isotherm equation as shown below.

$$
\frac{C_{e}}{\mathrm{q}_{\mathrm{e}}}=\frac{1}{K_{R}}+\frac{\alpha_{R}}{K_{R}} \cdot C_{e}^{\beta}
$$

where, $q_{e}$ is the solid phase adsorbent concentration in equilibrium $(\mathrm{mmol} / \mathrm{g}), C_{e}$ is the liquid phase adsorbent concentration in equilibrium (mmol/L), $K_{R}, \alpha_{R}$ and $\beta$ are the Redlich-Peterson isotherm constants and $\beta$ lies between 0 and 1.

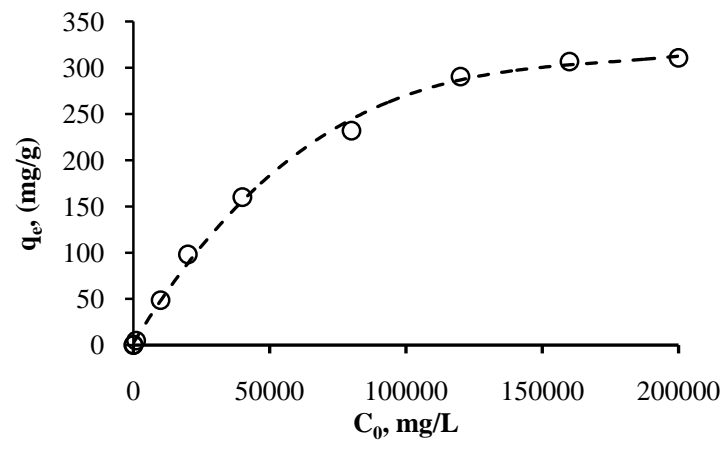

Fig. 3. Adsorption equilibrium for copper on INDION225H ion exchange resin

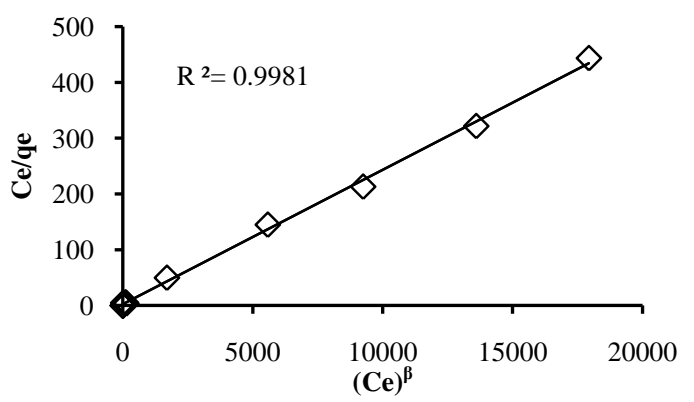

Fig. 4. Redlich-Peterson isotherm for adsorption of copper on INDION225H ion exchange resin

Redlich-Peterson isotherm for adsorption of copper on INDION225H is shown in Fig. 4. As it is three parameter model, direct linear curve fitting is not possible. So, the error minimization procedure is adopted to calculate isotherm constants and results are shown in Table I.

TABLE I: REDLICH-PETERSON ISOTHERM CONSTANTS FOR ADSORPTION OF COPPER ON INDION225H ION EXCHANGE RESIN

\begin{tabular}{cc}
\hline Model Parameter & $\begin{array}{c}\text { Redlich-Peterson Isotherm } \\
\text { constants }\end{array}$ \\
\hline $\mathrm{K}_{\mathrm{R}, \mathrm{L} / \mathrm{g}}$ & 286.13 \\
\hline$\alpha_{\mathrm{R},} \mathrm{L} / \mathrm{mg}$ & 6.94 \\
\hline$\beta$ & 0.827 \\
\hline
\end{tabular}

The fitted values of $\beta$ for INDION $225 \mathrm{H}$ is 0.828 , indicating it follows Langmuir's isotherm. Redlich-Peterson correlation coefficient is 0.998 , showing better fit than other isotherms.

\section{B. Bed Expansion Studies}

As feed velocity increases beyond the minimum fluidization velocity $U_{m f}$, the adsorbent bed begins to expand and the interstitial spaces between the particles in the bed increasingly open up. On increase in the liquid velocity the 
upward frictional drag on the particles increases making them to rise upwards. This increased inter-particle spaces (termed voidage) in the bed tend to reduce the interstitial velocity and hence the drag. Thus at any given velocity higher than $U_{m f}$, the bed expands and attains an equilibrium voidage whereby the net force of gravity and buoyancy of the bed is balanced by the drag.

Fig. 5 shows bed expansion with feed velocity for INDION225H and Fig. 6 shows Richardson-Zaki plot.

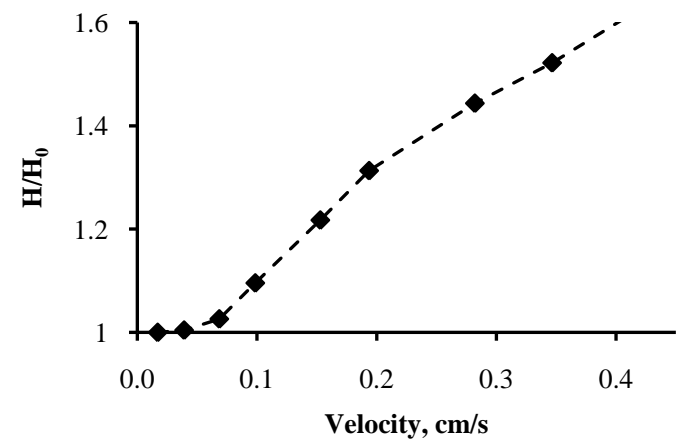

Fig. 5. Bed expansion studies of INDION225H in $2.5 \mathrm{~cm}$ diameter glass column

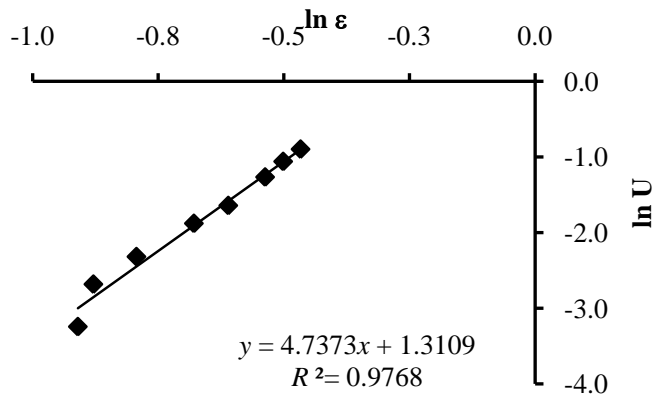

Fig. 6. Richardson-Zaki plot for expansion studies of INDION225H in $2.5 \mathrm{~cm}$ diameter glass column

The Richardson-Zaki (R-Z) equation states that a plot of $\ln U$ vs. $\ln \varepsilon$ would be a straight line with a slope of $n$ and y-axis intercept of $\ln U_{t}$, Form the plot in Fig. 6 the values of the Richardson-Zaki index and terminal settling velocity are found to be 4.7373 and $3.71 \mathrm{~cm} / \mathrm{s}$ respectively.

The linearity of the R-Z plot is often taken as a proof of smooth particulate fluidization. The particulate behavior of the expanded bed is essential if the bed is to be used for adsorptive separation. Any gross motion of liquid and solid phase in the bed would result in reduction of bed's adsorption and separation capacity.

\section{Dynamic Copper Adsorption in Packed and Expanded Beds}

Fig. 7 and Fig. 8 show the breakthrough curves for adsorption of $\mathrm{Cu}^{2+}$ in packed and expanded bed mode respectively and Fig. 9 show HETP curves for packed and expanded bed adsorption.

It is observed that as the velocity increases, HETP increases resulting in lowering the performance of the adsorption system. It is clear that an increase in liquid velocity decreases the residence time and increases the axial dispersion leading to deviation of systems away from the plug flow condition. This reduces overall effective mass transfer.

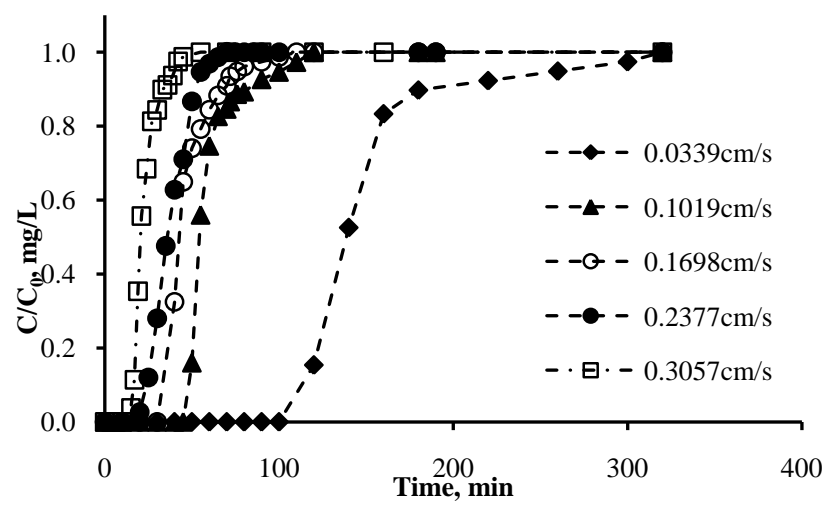

Fig. 7. Breakthrough curve for adsorption of copper on INDION225H in 2.5 $\mathrm{cm}$ diameter packed bed at different velocities

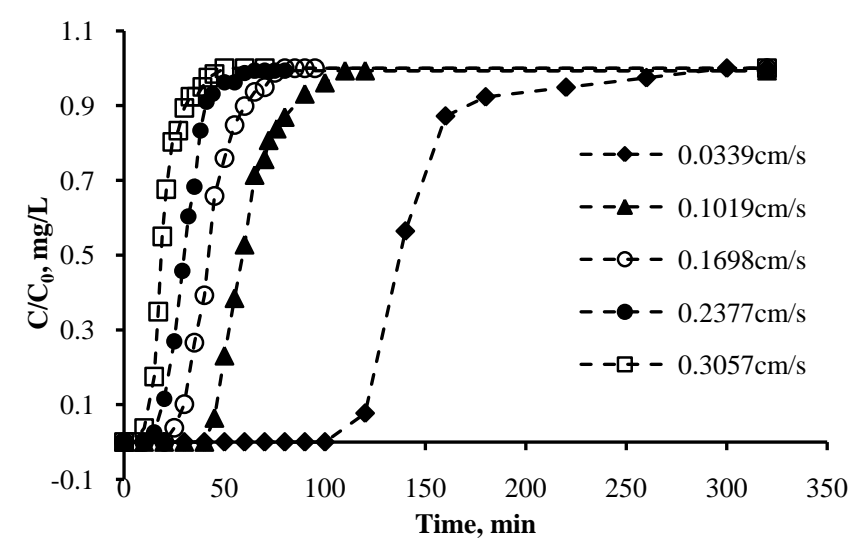

Fig. 8. Breakthrough curve for adsorption of copper on INDION225H in $2.5 \mathrm{~cm}$ diameter expanded bed at different velocities

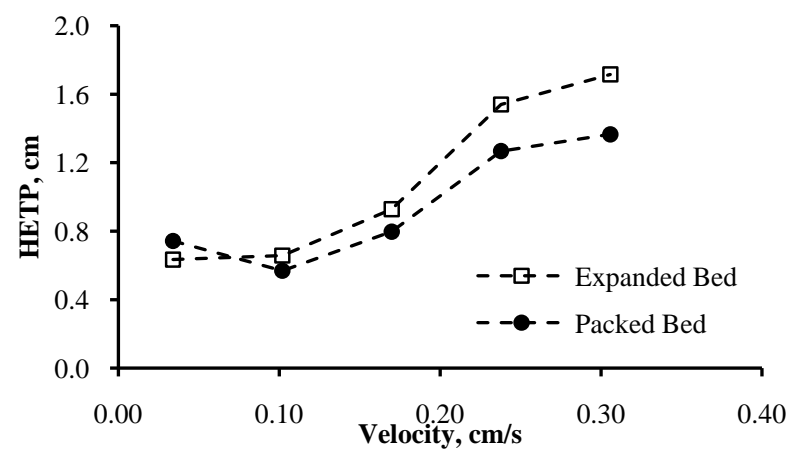

Fig. 9. Bed efficiency (HETP) for adsorption of copper on INDION225H in a $2.5 \mathrm{~cm}$ diameter column in packed and expanded beds

The dynamic adsorption capacity of INDION225H depends on feed velocity for packed bed as well as expanded bed. At a lower velocity, the breakthrough curve is broad, and it becomes steeper with an increase in velocity. This affects the bed efficiency, which is measured as HETP. Results show that, at a lower feed velocity packed and expanded bed gives an equivalent performance in terms of HETP. But at a higher feed velocity expanded bed gives lower HETP than that of the packed bed, the difference increases with the feed velocity. So, it is observed that the operation of expanded bed at lower velocity gives advantages over packed bed without major compromise on bed efficiency. Also, choosing high density adsorbent allows operating expanded bed at higher velocity. 


\section{CONCLUSIONS}

As the solid-liquid expanded bed behaves in principle like plug flow reactor or packed bed, liquid phase mixing in axial direction is minimum. Also it offers higher bed voidage so feed with insoluble matter can be handled without increasing pressure drop across the bed. It is observed that at a lower feed velocity packed and expanded bed gives an equivalent performance in terms of HETP. Solid and liquid phase backmixing lowers the bed performance, which increases with bed expansion and depends on adsorbent properties such as density, adsorption capacity etc.. Hence, proper choice of adsorbent and operating conditions can allow for carrying out adsorptive separations in the expanded bed mode for wastewater treatment with minimum impact on bed efficiency.

\section{NOMENCLATURE}

$\alpha_{R}$ : Constant of Redlich-Peterson isotherm ( $\left.\mathrm{L} / \mathrm{mg}\right)$

$C_{0}$ : Initial concentration of adsorbate $(\mathrm{mg} / \mathrm{L})$

$C_{e}$ : Equilibrium adsorbate concentration $(\mathrm{mg} / \mathrm{L})$

$E$ : Bed expansion

$f$ : Fractional ability of adsorbent to adsorb solute (Fraction) $H$ : Expanded bed height $(\mathrm{cm})$

$H_{0}$ : Sedimented bed height $(\mathrm{cm})$

HETP: Height Equivalent to Theoretical Plate $(\mathrm{cm})$

$K_{R}$ : Constant in Redlich-Peterson isotherm $(\mathrm{L} / \mathrm{g})$

$L$ : Column length $(\mathrm{cm})$

$L_{a}$ : Height of active adsorption zone $(\mathrm{cm})$

$N$ : Number of theretical plates

$n$ : Richardson-Zaki index

$q_{e}$ : Equilibrium adsorption uptake concentration $(\mathrm{mg} / \mathrm{g})$

$R^{2}$ : Correlation coefficient

$U$ : Superficial velocity $(\mathrm{cm} / \mathrm{s})$

$U_{t}$ : Terminal settling velocity $(\mathrm{cm} / \mathrm{s})$

$V_{B}$ : Volume of eluent at breakthrough point $(\mathrm{mL})$

$V_{E}$ : Volume of eluent at exhaust point $(\mathrm{mL})$

$V_{R}$ : Volume of eluent at inflection point $(\mathrm{mL})$

$W$ : Total solute loaded (g)

$W_{a}$ : Amount of solute adsorbed $(\mathrm{g})$

$\alpha$ : Area under the curve which is equivalent to unadsorbed volume

$\beta$ : Constant in Redlich-Peterson isotherm equation

$\varepsilon$ : Bed voidage (Fraction)

$\varepsilon_{0}$ : Sedimented bed voidage (Fraction)

\section{REFERENCES}

[1] N. B. Frej, R. Hjorth, and A. Hammarstrom, "Pilot scale recovery of recombinant Annexin V from unclarified Escherichia coli homogenate using expanded bed adsorption," Biotechnology and Bioengineering, vol. 44, no.8, pp. 922-929, Oct.1994.

[2] R. Bermejo, F. G. Acien, M. J. Ibanez, J. M. Fernandez, E. Molina, and J. M. Alvarez-Pez, "Preparative purification of B-phycoerythrin from the microalgae Porphyridium cruentum by expanded bed adsorption chromatography," Journal of Chromatography B, vol. 790, no.1-2, pp. 317 - 325, Jan.2003.

[3] P. Brixius, I. Mollerup, O. E. Jensen, M. Halfar, J. Thommes, and M. R Kula, "Expanded bed adsorption as a primary recovery step for the isolation of the insulin precursor MI3 process development and scale up," Biotechnology and Bioengineering, vol.91, no.3, pp.14-20, Nov.2005.

[4] Y. K. Chang, J. T. Horng, R. Z. Haung, and S. Y. Lin, "Direct capture of factor IX from unclarified human plasma by IMEBAC," Biochemical Engineering Journal, vol. 29, pp.12-22, April 2006.
[5] T. Charoenrat, M. C. Ketudat, M. Jahic, S. O. Enforce, and A. Veide, "Recovery of recombinant $\beta$-glucosidase by expanded bed adsorption from Pichia pastoris high-cell-density culture broth," Journal of Biotechnology, vol.122, pp. 86-98, March 2006.

[6] H. A. Chase and N. M. Draeger, "Expanded bed adsorption of proteins using ion exchangers," Separation Science and Technology, vol. 27, no.14, pp. 2021-2039, 1992.

[7] H. A. Chase, "Purification of proteins by adsorption chromatography in expanded Beds," Trends in Biotechnology, vol.12, pp. 296-303, August 1994.

[8] W. S. Choe, R. H. Clemmitt, H. A. Chase, and A. P. J. Middelberg, "Coupling of chemical extraction and expanded bed adsorption for simplified inclusion body processing: Optimization using surface plasmon resonance," Biotechnology and Bioengineering, vol. 81, no. 2, pp. 221-232, Nov. 2002.

[9] S. Rengaraj, Y. Kim, C. K. Joo, K. Choi, and J. Yi, "Batch adsorptive removal of copper ions in aqueous solutions by ion exchange resins: 1200H and IRN97H," Korean J. Chem. Eng., vol. 21, pp. 187-194, Jan. 2004.

[10] Y. Omer, A. Yalcin, and G. Fuat, "Removal of copper, nickel, cobalt and manganese from aqueous solution by kaolinite," Water Res., vol. 37, pp. 948 , Feb. 2003.

[11] R. Hjorth, "Expanded-bed adsorption in industrial bioprocessing: recent developments," Trends Biotechnol., vol.15, pp. 230-235, June 1997.

[12] J. Hubbuch, J. Thommes, and M. R. Kula, "Biochemical engineering aspects of expanded bed adsorption," Adv. Biochem. Eng. Biotechnol., vol. 92, pp.101-123, 2005.

[13] G. E. Hamilton, F. Luechau, S. C. Burton, and A. Lyddiatt, "Development of a mixed mode adsorption process for the direct product sequestration of an extracellular protease from microbial batch cultures," J. Biotechnol., vol. 79, pp.103-115, April 2000.

[14] R. Hjorth, S. Kampe, and M. Carlsson, "Analysis of some operating parameters of novel adsorbent for recovery of proteins in expanded beds," Bio-separation, vol. 5, pp. 217-223, 1995.

[15] C. Karau, J. Benken, and M. R. Kula, "The Influence of Particle Size Distribution and Operating Conditions on the Adsorption Performance in Fluidized Beds," Biotechnology and Bioengineering, vol.5 5, no. 1, pp. 54-64, July 1997.

[16] O. Redlich and D. L. Peterson, “A useful adsorption isotherm," J. Phys. Chem., vol. 63, pp. 1024-1024, June 1959.

[17] H. F. Xia, D. Q. Lin, and S. J. Yao, "Evaluation of new high density ion exchange adsorbents for expanded bed adsorption chromatography," Journal of Chromatography A, vol. 1145, pp. 58-66, March 2007.

[18] A. Gaikwad, "Ion Exchange process for purification modeling and scale up," M. Chem. Engg. Thesis, Dept. Chem. Eng., University of Mumbai, 2004.

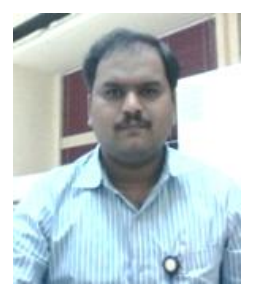

solid-liquid fluidization.

Yogeshwar N. Thakare received his Masters in Chemical Engineering from Institute of Chemical Technology Matunga Mumbai, India in 2007. Currently he is working as Technologists with Reliance Technology Group, Reliance Industries Ltd. Hazira and also pursuing Ph.D. in Chemical Engineering from Sardar Vallabhbhai National Institute of Technology, Surat. He has research experience in the area of polyolefin's catalysis and

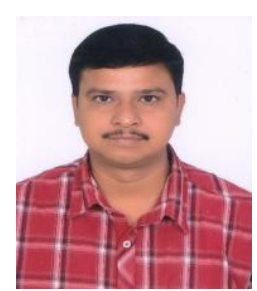

Arun Kumar Jana was born in February 1977 in India. He did his B.Tech. in Chemical Technology with specialization in Petrochemicals and Petroleum Refinery Engineering from Department of Chemical Technology, University of Calcutta, Kolkata in 2001. Then he did M.Tech. in Petrochemicals and Petroleum Refinery Engineering from the same department in 2002. He received his Ph.D in Chemical Engineering from Indian Institute of Technology Kharagpur (IITKGP), India in 2008 in the area of Multiphase Flow. He joined Sardar Vallabhbhai National Institute of Technology as an Assistant Professor of Chemical Engineering Department in August 2007. His current work mainly involves liquid-solid fluidization and Computational Fluid Dynamics based modeling. He is a life associate member of Indian Institute of Chemical Engineers. 